\title{
Ayrıştırma Yöntemlerinin Derin Öğrenme Algoritması ile Tanımlanan Rüzgâr Hızı Tahmin Modeli Başarımına Etkisinin İncelenmesi
}

\author{
Aytaç Altan ${ }^{1 *}$, Seçkin Karasu \\ ${ }^{1 *}$ Zonguldak Bülent Ecevit Üniversitesi, Mühendislik Fakültesi, Elektrik Elektronik Mühendisliği Bölümü, Zonguldak, Türkiye (ORCID: 0000-0001-7923-4528), \\ aytacaltan@beun.edu.tr \\ ${ }^{2}$ Zonguldak Bülent Ecevit Üniversitesi, Mühendislik Fakültesi, Elektrik Elektronik Mühendisliği Bölümü, Zonguldak, Türkiye (ORCID: 0000-0001-5277-5252), \\ seckin.karasu@beun.edu.tr
}

(İlk Geliş Tarihi 26 Ağustos 2020 ve Kabul Tarihi 24 Aralık 2020)

(DOI: $10.31590 /$ ejosat.785699)

ATIF/REFERENCE: Altan, A. \& Karasu, S. (2020). Ayrıștırma Yöntemlerinin Derin Öğrenme Algoritması ile Tanımlanan Rüzgâr Hızı Tahmin Modeli Başarımına Etkisinin İncelenmesi. Avrupa Bilim ve Teknoloji Dergisi, (20), 844-853.

$\ddot{O} \mathbf{z}$

Son on yılda, rüzgâr enerjisine dayalı yenilenebilir enerji kaynaklarının kullanımındaki kayda değer artış, bu kaynakların ihtiyaçlara kesintisiz ve tahmin edilebilir bir şekilde cevap verebilmesini sağlamak için rüzgâr hızı tahmin çalışmalarının önemini arttırmaktadır. Rüzgâr enerjisinden teknolojik olarak faydalanmak için; yararlanma imkânlarının bilinmesi, yüksek rüzgâr enerjisi potansiyeline sahip bölgelerin belirlenmesi, rüzgâr karakteristiklerinin ve hızlarının tahmin edilebilir olması oldukça önemlidir. Güvenilir ve yüksek hassasiyetli rüzgâr hızı tahmini, rüzgâr gücünün verimli kullanımı ve kullanılması açısından hayati önem arz etmektedir. Rüzgâr hızının durağan olmaması ve stokastik yapısı, rüzgâr hızı tahmininde ayrıştırma yöntemlerini ön plana çıkarmaktadır. Bu çalışmada, ayrıştırma yöntemlerinden ampirik kip ayrışımı, topluluk ampirik kip ayrışımı ve ampirik dalgacık dönüşümünün derin öğrenme yöntemlerinden uzun-kısa süreli bellek ile elde edilen rüzgar hızı tahmin modeli başarımına etkisi incelenmektedir. Türkiye'nin Marmara bölgesindeki üç rüzgâr istasyonundan toplanan veriler her bir ayrıştırma yöntemi ile alt bant sinyallerine ayrıştırılarak uzun-kısa süreli bellek model yapısı ile kombine rüzgâr hızı tahmin modeli oluşturulmaktadır. Her bir ayrıştırma yöntemi ile birlikte elde edilen kombine modellerin başarımları istatistiksel hata ölçütlerine göre değerlendirilmekte ve rüzgâr hızı tahmin modeli başarımına etkisi en yüksek ayrıştırma yöntemi, melez rüzgâr hızı tahmin modeli elde edilmesi çalışmalarında önerilmektedir.

\section{Investigation of the Effect of Decomposition Methods on Wind Speed Forecasting Model Performance Defined by Deep Learning Algorithm}

\begin{abstract}
In the last decade, the significant increase in the use of renewable energy sources based on wind energy has increased the importance of wind speed forecasting studies to ensure that these resources can respond to the needs in an uninterrupted and predictable manner. In order to be able to utility from wind energy technologically, it is very important to knowing the facilities of utilization, determining the regions, which have high potential of wind energy, being predictable the wind characteristics and speeds. The reliable and high accuracy wind speed forecasting is of vital to the efficient exploitation and utilization of wind power. The non-stationary and stochastic structure of the wind speed raise to the forefront the decomposition methods in wind speed forecasting. In this study, the effect of empirical mode decomposition, ensemble empirical mode decomposition and empirical wavelet transform on the performance of wind speed forecasting model obtained with long-short term memory from deep learning methods is investigated. The data collected from five wind farms in Marmara region, Turkey are decomposed to subband signal by these three decomposition methods, and the combined wind speed
\end{abstract}

*Sorumlu Yazar: aytacaltan@beun.edu.tr 
forecasting model is obtained with the long-short-term memory model structure. The performance of the combined models obtained by each decomposition method has been evaluated according to the statistical error criteria, and the decomposition method that is the highest effective to performance of wind speed forecasting model is suggested for the studies of obtaining the hybrid wind speed forecasting model.

Keywords: Wind speed, Forecasting model, Decomposition methods, Deep learning, Long-Short Term Memory, Empirical Wavelet Transform.

\section{Giriş}

Atmosferin alt katmanlarını kirleten diğer bütün fosil kökenli enerji kaynaklarına kıyasla temiz bir enerji kaynağı olan rüzgâr enerjisi, dünyanın en hızlı büyüyen alternatif enerji teknolojilerinden biridir. Rüzgâr enerjisinin 2020 yılına kadar yenilenebilir enerjinin yaklaşık \%40'ını sağlayan en önemli yenilenebilir enerji kaynağı haline geleceği öngörülmektedir (Scarlat et al. 2015). Türkiye'nin tahmin edilen ekonomik rüzgâr enerji potansiyelinin yaklaşık $50.000 \mathrm{MW}$ olduğu, kurulu sistem kapasitesinin ise bu değerin yaklaşık \%10'u civarında olduğu bilinmektedir (Çakır 2010). Rüzgâr enerjisinden etkin bir şekilde faydalanılabilmesi için yüksek rüzgâr enerjisi potansiyeline sahip bölgelerin belirlenmesi, rüzgâr karakteristiklerinin ve hızlarının yüksek doğrulukla tahmin edilmesi gerekmektedir. Rüzgâr rejiminin güvenilir ve yüksek doğrulukla modellenmesinde, rüzgâr hızının durağan olmaması ve stokastik yapısı nedeniyle tekli modellerin tahmin başarımlarının belirli bir seviyenin altında kaldıkları görülmektedir. Bu çalışmada, melez rüzgâr hızı tahmin modellerinde sıklıkla kullanılan ayrıştırma yöntemlerinden ampirik kip ayrıştırma (empirical mode decomposition-EMD), topluluk ampirik kip ayrıştırma (ensemble empirical mode decomposition-EEMD) ve ampirik dalgacık dönüşümünün (empirical wavelet transform-EWT) derin öğrenme yöntemlerinden uzun-kısa süreli bellek (long-short term memoryLSTM) ile elde edilen rüzgar hızı tahmin modeli başarımına etkisi incelenmektedir.

Rüzgâr enerjisi kullanım sürecinde yüksek doğrulukla rüzgâr hızı tahmini, rüzgâr çiftliği tasarımı ve elektrik şebekesinin işletimi açısından kritik öneme sahiptir (Liu et al. 2018). Fiziksel, istatistiksel ve yapay zekaya dayalı tekli modellerle birlikte ayrıştırma ve optimizasyon yöntemlerini içeren melez modeller rüzgâr hızı tahmininde sıklıkla kullanılmaktadır (Lange and Focken 2006; De Giorgi et al. 2011; Karasu et al. 2017; Li and Shi 2010; Li et al. 2018).

Fiziksel modeller, arazi, engel, engebe, atmosferik basınç ve ortam sıcaklığı gibi fiziksel veriler yardımıyla uzun vadeli rüzgâr hızı tahmininde kullanılmaktadır. Ayrıca, fiziksel modeller rüzgâr hızı tahmininde istatistiksel modellerin yardımcı girişi olarak da sıklıkla kullanılmaktadır. Hesaplama işlemlerinde yüksek maliyete ve hesaplama karmaşıklığına sahip olan fiziksel modellerin kısa vadeli rüzgâr hızı tahmininde yetersiz kaldığ bilinmektedir (Du et al. 2017). Kısa vadeli rüzgâr hızı tahmininde, geçmiş rüzgâr hızı zaman serisi verilerini kullanan istatistiksel yöntemler sıklıkla tercih edilmektedir. Kısa vadeli rüzgâr hızı tahmininde kullanılan istatistiksel yöntemler doğrusal ve doğrusal olmayan modelleri içermektedir. Doğrusal modeller arasında doğrusal regresyon, otoregresif (autoregressive-AR), Kalman filtreleme, otoregresif hareketli ortalama (autoregressive moving average-ARMA), otoregresif bütünleşik hareketli ortalama (autoregressive integrated moving average-ARIMA) modelleri yer almaktadır (Riahy and Abedi 2008; Akçay and Filik 2017; Sfetsos 2010; Cadenas et al. 2016). Rüzgâr hızının durağan olmaması ve stokastik yapısı nedeniyle bu modeller yardımıyla elde edilen rüzgâr hızı tahmin modellerinin başarımı tatmin edici seviyede olmamaktadır. Rüzgâr hızı zaman serisi verilerinin doğrusal olmayan yapısı nedeniyle doğrusal olmayan otoregresif (nonlinear autoregressive-NAR) ve doğrusal olmayan otoregresif dış kaynaklı (nonlinear autoregressive exogenous-NARX) modelleri rüzgâr hızı tahmininde kullanılmaktadır (Karasu et al. 2017; Karasu et al. 2017b).

Rüzgâr hızı zaman serilerinin doğrusal olmayan karakteristiklerinin yakalanarak rüzgâr hızının yüksek doğrulukla tahmin edilebilmesi için yapay zekâya dayalı yöntemler kullanılmaktadır. Bu yöntemler arasında yapay sinir ağı (artificial neural network-ANN), bulanık mantık (fuzzy logic-FL), çok katmanlı algılayıc1 (multi-layer perceptron-MLP), geri yayılmalı sinir ağı (back propagation neural network-BPNN), Elman sinir ağı (Elman neural network-ENN), evrişimli sinir ağ (convolutional neural network-CNN), tekrarlayan sinir ağ1 (recurrent neural network-RNN), LSTM ağ1 ve dalgacık sinir ağı (wavelet neural network-WNN) yer almaktadır (Li and Shi 2010; Mohandes et al. 2011; Liu et al. 2015; Sun and Wang 2018; Liu et al. 2015; Chen et al. 2018). Rüzgâr hızı tahmininde bu yöntemler tekli model olarak kullanılabildiği gibi melez modeller içerisinde de kullanılabilmektedir (Liu et al. 2012; Liu et al. 2018; Liu et al. 2018b).

Ayrıştırma yöntemleri ve optimizasyon algoritmaları ile birlikte yapay zekaya dayalı modelleri içeren melez yapıdaki rüzgâr hızı tahmin modelleri tekli modellere göre daha yüksek başarımla rüzgâr hızını tahmin edebilmekte, rüzgâr hızı zaman serilerinin belirsizliği ve durağan olmayan yapısı ile daha etkin biçimde başa çıkabilmektedir (Liu et al. 2015; Ma et al. 2017). Melez yapıda rüzgar hızı tahmin modellerinin elde edilmesinde farklı ayrıştırma yöntemleri ve optimizasyon yöntemleri ayrı ayrı yada birlikte kullanılmaktadır. Yu ve arkadaşları (Yu et al. 2017) tarafından rüzgar hızı tahmin modelinin doğruluğunun iyileştirilmesinde EMD, EEMD ve uyarlamalı gürültü ile komple topluluk ampirik kip ayrıştırma (complete ensemble empirical mode decomposition with adaptive noise-CEEMDAN) yöntemlerinin ENN modeli üzerindeki etkisi incelenmektedir. Rüzgâr hızı zaman serileri ayrıştırma yöntemleri ile alt bantlarına ayrılmakta ve en yüksek frekans verilerinin daha ileri düzeyde ele alınabilmesi için tekil spektrum analizinden (singular spectrum analysis-SSA) faydalanılmaktadır. CEEMDAN ayrıştırma yönteminin diğer iki ayrıştırma yöntemine göre rüzgâr hızı tahmin modelinin performansını daha fazla iyileştirdiği belirtilmektedir. Yüksek hassasiyetli ve çok adımlı rüzgâr hızı tahmini için Liu ve arkadaşları (Liu et al. 2015) tarafından hızlı topluluk ampirik kip ayrıştıma (fast ensemble empirical mode decompositionFEEMD), MLP ve zihinsel evrimsel optimizasyon algoritması içeren melez bir rüzgâr hızı tahmin modeli önerilmektedir. Rüzgâr hızı zaman serileri FEEMD algoritması ile bir dizi alt bantlara ayrıştırılmaktadır. Zihinsel evrimsel algoritma (mind evolutionary algorithm-MEA) tarafından optimize edilen MLP sinir ağları ile ayrıştırılan her bir rüzgâr hızı alt bandı tahmin edilmektedir. FEEMD algoritmasının, MLP sinir ağlarının tahmin 
performansını önemli ölçüde arttırdığı belirtilmektedir. Liu ve arkadaşları (Liu et al. 2018) tarafından güvenilir ve yüksek hassasiyetli rüzgâr hızı tahmini için dalgacık paketi ayrıştırma (wavelet packet decomposition-WPD), CNN ve LSTM tabanlı melez rüzgâr hızı tahmin modeli önerilmektedir. Önerilen modelde rüzgâr hızı zaman serileri WPD yardımıyla bir dizi alt bantlara ayrıştırılmaktadır. Elde edilen en yüksek frekanslı alt bantların tahmini bir boyutlu CNN algoritması ile gerçekleştirilmektedir. Düşük frekanslı bantların tahmininde ise CNN-LSTM melez derin öğrenme algoritması kullanılmaktadır. Özellikle rüzgâr hızının ani değişimlerinin tahmin edilmesinde önerilen yöntemin iyi tahmin performansına sahip olduğu ifade edilmektedir. Rüzgâr hızı tahmin modellerinde tahmin doğruluğunun arttırılabilmesi için rüzgâr hızı zaman serilerindeki doğrusal olmayan ve durağan olmayan durumların azaltılması gerekmektedir. Gerçek zamanlı ayrıştırmaya dayalı tahmin modellerinde tahmin performansına etki eden faktörler Jiang ve Huang (Jiang and Huang 2017) tarafindan incelenmektedir. Özellik seçimi ve hata düzeltme ile birlikte kullanılan EMD algoritmasının, rüzgâr hızı zaman serilerindeki doğrusal olmayan ve durağan olmayan durumları azalttığı belirtilmektedir. Önerilen modelin gerçek zamanlı ayrıştırmaya dayalı rüzgâr hızı tahmin modeli performansını iyileştirdiği ifade edilmektedir. Literatürdeki çalışmalar incelendiğinde özellikle son zamanlarda rüzgâr hızı tahmin modeli elde edilmesinde ayrıştırma yöntemlerinin melez model yapıları içerisinde sıklıkla kullanıldığı görülmektedir. Yapılan çalışmalarda, ayrıştırma yöntemlerinin rüzgâr hızı zaman serilerindeki doğrusal olmayan ve durağan olmayan durumları azaltmada etkin olduğu belirtilmektedir.

Rüzgâr hızı tahmininde tekli modellerin tahmin performansının melez modellerin tahmin performansına göre daha düşük olduğu yapılan çalışmalardan bilinmektedir (Liu et al. 2012; Liu et al. 2018; Liu et al. 2018b). Ancak, derin öğrenme yöntemleri ile oluşturulan tekli rüzgâr hızı tahmin modellerinin tahmin başarımlarının diğer tekli rüzgâr hızı tahmin modellerinin tahmin başarımına göre daha iyi olduğu ifade edilmektedir ( $\mathrm{Hu}$ and Chen 2018). Ayrıştırma yöntemlerinin derin öğrenme algoritması ile oluşturulan modeller üzerindeki etkisinin belirlenmesi, rüzgâr hızının yüksek doğrulukla tahmin edilmesinde kritik rol oynamaktadır. Bu çalışmada, rüzgâr hızı tahmin modeli oluşturulmasında sıklıkla kullanılan üç ayrıştırma yönteminin derin öğrenme yöntemlerinden LSTM ile oluşturulan tahmin modeli üzerindeki etkisi incelenmektedir. Tekli derin öğrenme modelinin başarımı ve her bir ayrıştırma yöntemi ile birlikte elde edilen melez modellerin başarımları istatistiksel hata ölçütlerine göre değerlendirilmekte ve rüzgâr hızı tahmin modeli performansına en fazla iyileştirici katkı sağlayan ayrıştırma yöntemi gerçek zamanlı melez rüzgâr hızı tahmin modeli elde edilmesi çalışmaları için önerilmektedir. Çalışmanın geri kalan kısmı şu şekilde organize edilmiştir. Çalışmanın ikinci bölümünde, EMD, EEMD ve EWT ayrıştırma algoritmaları ve bu algoritmaların rüzgâr hızı zaman serileri için LSTM algoritmasına nasıl uygulandığ1 belirtilmektedir. Üçüncü bölümde, EMD, EEMD ve EWT ayrıştırma algoritmaları ile oluşturulan derin öğrenme modelleri sunulmaktadır. Dördüncü bölümde, önerilen ayrıştırma yöntemi ile elde edilen melez modelin ve diğer ayrıştırma yöntemleri ile elde edilen melez modellerin deneysel sonuçları sunulmakta ve tartışılmaktadır. Son olarak, çalışmanın sonuçları beşinci bölümde vurgulanmaktadır.
$\mathrm{Bu}$ bölümde, rüzgâr hızı tahmini için oluşturulan melez modellerin içerisinde yer alan EMD, EEMD ve EWT ayrıştırma algoritmaları açıklanmaktadır.

\subsection{Ampirik Kip Ayrıştırma}

Doğrusal olmayan ve durağan olmayan sinyalleri işlemek için Huang ve arkadaşları (Huang et al. 1998) tarafindan geliştirilen EMD tekniğinde, karmaşıklık durumuna bağlı olarak verilerin aynı anda birçok farklı eş zamanlı salınım moduna sahip olabileceği varsayılmaktadır. $\mathrm{Bu}$ içsel modlar orijinal zaman serilerinden verilerin yerel karakteristik ölçeğine dayanılarak çıkarabilmektedir. Her bir içsel mod aşağıdaki iki koşulu sağlayan bir içsel mod fonksiyonu (intrinsic mode function-IMF) olarak ifade edilebilir (Zhang et al. 2008):

- Fonksiyonlar aynı sayıda ekstremum ve sıfır geçişe sahiptir veya en fazla bir farklılık gösterir;

- Fonksiyonlar, yerel sıfır ortalamasına göre simetriktir.

Belirtilen bu iki koşul bir IMF'nin hemen hemen periyodik bir fonksiyon olmasını ve ortalamanın sifira ayarlanmasını sağlamaktadır. Bir $x(t)$ sinyali verildiğinde, EMD'nin etkin algoritması aşağıdaki gibi tanımlanabilir.

(i) $\quad x(t)$ zaman serisinin tüm ekstremumları tanımlanır,

(ii) Üst ve alt zarflar $\left(e_{\min }(t)\right.$ ve $\left.e_{\max }(t)\right)$ kübik spline interpolasyonuyla oluşturulur,

(iii) Ortalama $m(t)=\left(e_{\min }(t)+e_{\max }(t)\right) / 2$ hesaplanır,

(iv) $x(t)$ zaman serisi ortalama zaman serisinden çıkarılır ve $d(t)=x(t)-m(t)$ olarak tanımlanır,

(v) $d(t)$ 'nin özellikleri kontrol edilir;

- $d(t)$ bir IMF ise; $d(t)$ i'ninci IMF olarak belirlenir ve $x(t)$, kalıntı $(r(t)=x(t)-d(t))$ ile değiştirilir,

- $d(t)$ bir IMF değil ise; $x(t), d(t)$ ile değiştirilir.

(vi) $r(t)$, durma şartlarını (Huang et al. 2003) yerine getirene kadar (i)-(v) adımları tekrarlanır.

\subsection{Topluluk Ampirik Kip Ayrıştırma}

Durağan olmayan ve/veya doğrusal olmayan sinyal işlemede yaygın olarak kullanılan EMD yönteminin genellikle geniş ölçüde farklı ölçeklerden oluşan tek bir IMF veya farklı IMF bileşenlerinde bulunan benzer bir ölçeğin sinyalinden oluşan tek bir IMF olarak tanımlanan mod karışımından sıkıntı yaşadığ bilinmektedir. $\mathrm{Bu}$ sorunun üstesinden gelmek için Wu ve Huang (Wu and Huang 2009) tarafindan EEMD önerilmiştir. EEMD, gerçek IMF bileşenlerini bir dizi denemenin ortalaması olarak tanımlamaktadır. Her deneme, sinyalin ayrışma sonuçlarına ilave olarak bir sonlu genlikli beyaz gürültüden oluşmaktadır. Beyaz gürültü, tüm zaman-frekans alanını farklı ölçeklerin oluşturucu bileşenleri ile eşit olarak doldurmaktadır. Homojen dağılmış beyaz arka plana sinyal eklendiğinde, farklı ölçeklerdeki sinyal bitleri otomatik olarak arka plandaki beyaz gürültü tarafından belirlenen uygun referans ölçeklerine yansıtılmaktadır. Her denemedeki gürültü ayrı denemelerde farklı olduğundan, toplulukta yeterli denemelerin ortalaması iptal edilir. Topluluk ortalaması gerçek cevap olarak kabul edilir. Çünkü topluluğa daha fazla deneme eklendikçe, sonuçta tek kalıcı kısım sinyaldir. Burada ileri sürülen kritik kavram aşağıdaki gözlemlere dayanmaktadır:

\section{Ayriştırma Yöntemleri}


- Beyaz gürültünün toplamı, zaman-uzay topluluğu ortalamasında birbirini yok eder; bu nedenle, gürültü eklenmiş son sinyal topluluğu ortalamasında sadece sinyal hayatta kalır.

- Topluluğu mümkün olan tüm çözümleri tüketmeye zorlamak için bölünemeyecek kadar küçük olmayan sonlu genlik beyaz gürültü gereklidir; sonlu büyüklük gürültüsü, farklı ölçek sinyallerinin ikili filtre bankaları tarafından dikte edilen ilgili IMF'de kalmasını sağlar ve ortaya çıkan topluluğun ortalamasını daha anlamlı hale getirir.

- EMD için gerçek ve fiziksel olarak anlamlı cevap gürültüsüz değildir; gürültü eklenmiş sinyalden oluşan çok sayıda denemenin topluluk ortalaması olarak belirlenmiştir.

EEMD, sonlu genlikli beyaz gürültünün farklı gerçekleşmelerine eklenen bir veri ayrıştırma grubundan oluşur ve daha sonra nihai sonuç olarak farklı ayrışmalardan karşılık gelen IMF'lerin araçlarını alır. EEMD, "gerçek" IMF bileşenlerini, orijinal $x[n]$ sinyaline sonlu varyansın beyaz gürültüsünün farklı gerçekleşmelerinin eklenmesi ile oluşturulan denemelerin bir topluluğu üzerinden EMD aracılığıyla elde edilen IMF'lerin ortalaması olarak tanımlar. EEMD algoritması aşağıda sunulmaktadır.

(i) $x^{(i)}=x+\beta w^{(i)}$ üretilir. Burada $\beta>0$ ve $w^{(i)}(i=$ $1, \ldots, I$ ) beyaz Gauss gürültüsü (white Gaussian noise-WGN)'nün farklı gerçekleşmeleridir,

(ii) Her $x^{(i)}(i=1, \ldots, I)$ EMD tarafından ayrıştılarılır ve $d_{k}^{(i)}$ modları elde edilir. Burada $k=1, \ldots, K$ modları ifade eder,

(iii) $x$ 'in $k$ 'nıncı moduna karşılık gelen $\bar{d}_{k}$ alınır, karşılık gelen modların ortalaması elde edilir,

$$
\bar{d}_{k}=\frac{1}{I} \sum_{i=1}^{I} d_{k}^{(i)}
$$

$\widehat{\psi}_{n}(\Omega)=\left\{\begin{array}{c}1 \\ \cos \left[\frac{\pi}{2} \alpha\left(\frac{1}{2 \tau_{n+1}}\left(|\Omega|-\Omega_{n+1}+\tau_{n+1}\right)\right)\right] \\ \sin \left[\frac{\pi}{2} \alpha\left(\frac{1}{2 \tau_{n}}\left(|\Omega|-\Omega_{n}+\tau_{n}\right)\right)\right] \\ 0\end{array}\right.$

$$
\begin{aligned}
& \text { eğer }(1+\rho) \Omega_{n} \leq|\Omega| \leq(1-\rho) \Omega_{n+1} \\
& \text { e } \breve{g} e r(1-\rho) \Omega_{n+1} \leq|\Omega| \leq(1+\rho) \Omega_{n+1} \\
& \text { ĕger }(1-\rho) \Omega_{n} \leq|\Omega| \leq(1+\rho) \Omega_{n}
\end{aligned}
$$

$\hat{\phi}_{n}(\Omega)=\left\{\begin{array}{c}1 \\ \cos \left[\frac{\pi}{2} \alpha\left(\frac{1}{2 \tau_{n}}\left(|\Omega|-\Omega_{n}+\tau_{n}\right)\right)\right] \\ 0\end{array}\right.$

e $\breve{\mathrm{g}} \operatorname{er}|\Omega| \leq(1-\rho) \Omega_{n}$

ĕger $(1-\rho) \Omega_{n} \leq|\Omega| \leq(1+\rho) \Omega_{n}$

aksi durumda

Denklem 2 ve 3 ile tanımlanabilmektedir. Burada, $\alpha(x)$ rastgele bir fonksiyondur ve

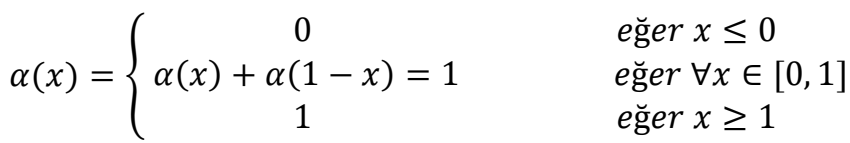

olarak tanımlanmıştır. Dar çerçevenin durumu, 
$\rho<\min _{n}\left(\frac{\Omega_{n+1}-\Omega_{n}}{\Omega_{n+1}+\Omega_{n}}\right)$

olarak ifade edilebilmektedir. Katsayılar yaklaşık olarak ampirik dalgacık ve ampirik ölçekleme fonksiyonları ile uygulanan $y(t)$ sinyalinin iç çarpımından elde edilmektedir.

\section{Melez Rüzgâr Hızı Tahmin Modelleri}

Bu bölümde, çalışmada ele alınan ayrıştırma yöntemlerinin derin öğrenme alanında kullanılan ve yapay bir tekrarlayan sinir ă̆ mimarisine sahip olan LSTM üzerindeki etkisinin incelenebilmesi için her bir ayrıştırma yöntemi ve LSTM algoritmasından oluşan melez rüzgâr hızı tahmin modelleri oluşturulmaktadır. Tahmin modellerinin oluşturulması için Türkiye'nin Marmara bölgesi çevresindeki üç farklı meteoroloji istasyonundan toplanan rüzgâr hızı verilerine ait istatistiksel değerler sunulmaktadır. Oluşturulan rüzgâr hızı tahmin modellerinin başarımının değerlendirilmesinde kullanılan performans ölçütleri de bu bölümde verilmektedir.

\subsection{Uzun-Kısa Süreli Bellek}

Tekrarlayan sinir ağlarının özel bir türü olarak, LSTM ağı uzun ve kısa vadeli bağımlılık problemlerini çözmede istikrarlı ve güçlü bir yeteneğe sahiptir. Doğrusal olmayan sıralı verileri işlemedeki başarısı ile uzun ve kısa vadeli bağımlılık problemlerini güçlü bir şekilde ele alabilen RNN'nin özel bir tipi olan LSTM sinir ağı, sadece bitişik geçici bilgileri tutmakla kalmaz aynı zamanda uzun vadeli bilgileri de kontrol eder. LSTM mimarisi Şekil 1'de sunulmuştur.

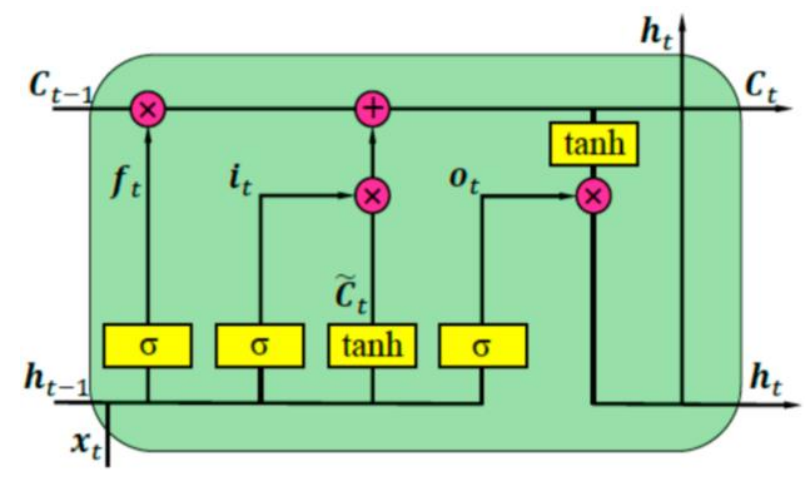

SSekil 1. LSTM mimari yapisl.

Geleneksel nöronların gizli katmanlarının yerini alan bellek hücresi, LSTM ağının çekirdeğidir (Hochreiter and Schmidhuber 1997). Giriş kapıları, çıkış kapıları ve unutma kapıları nedeniyle, LSTM ağı hücre durumuna bilgi ekleyebilir veya çıkarabilir. LSTM ağ yapısında, hücreye biriktirilebilecek yeni bilgileri tanımlamak için, giriş verileri giriş kapısının çıkışı ile çarpılmaktadır. Ağa yayılabilen bilgileri hesaplamak için, ağın çıkış verisi, çıkış geçidinin aktivasyonu ile çarpılmaktadır. Hücrenin son durumunun unutulup unutulmayacağını belirlemek için, önceki zamanın hücre durumları, unutma geçidinin aktivasyonu ile çarpılmaktadır. Hücrenin durumunu güncelleme ve LSTM ağının çıktısını hesaplama yöntemi aşağıda sunulmaktadir (Sainath et al. 2015):

- hücre durumundan hangi bilgilerin atılacağına karar verme aşamasi: $x_{t}$ ve $h_{t-1}$ değeri elde edilmekte ve bir $f_{t}$ sigmoid fonksiyon aracılığıyla atılıp atılmayacağı belirlenmektedir.

$$
f_{t}=\sigma\left(w_{f} \cdot\left[h_{t-1}, x_{t}\right]+b_{f}\right)
$$

- hangi yeni bilginin hücre durumunda depolanacağını belirleme aşaması: Sigmoid bir katman tarafından hücre durumunda saklanacak olan bilgiye karar verilmektedir. $x_{t}$ ve $h_{t-1}$ ile $\tanh (\cdot)$ tarafindan elde edilen değerler yeni bir aday değeri $\tilde{C}_{t}$ olarak alınır.

$$
\begin{aligned}
& i_{t}=\sigma\left(w_{i} \cdot\left[h_{t-1}, x_{t}\right]+b_{i}\right) \\
& \tilde{C}_{t}=\tanh \left(w_{C} \cdot\left[h_{t-1}, x_{t}\right]+b_{C}\right)
\end{aligned}
$$

- önceki hücre durumu $C_{t-1}$ 'yi yeni hücre durumu $C_{t}$ 'ye güncelleme aşaması: $C_{t-1}$ hücre durumu, unutmaya karar verilen bilgileri unutmak için $f_{t}$ ile çarpılır. Yeni bir hücre durumu $C_{t}$ elde etmek için, $i_{t}$ terimi $\tilde{C}_{t}$ ile çarpilır ve elde edilen terim bir önceki terime eklenerek yeni hücre durumu $C_{t}$ belirlenmektedir.

$$
C_{t}=f_{t} * C_{t-1}+i_{t} * \tilde{C}_{t}
$$

- hangi bilginin çıkış olacağına karar verme aşaması: Sigmoid bir tabaka tarafindan hangi bilginin hücre durumunda çıkış olacağına karar verilir.

$$
\begin{aligned}
& s_{t}=\sigma\left(w_{o} \cdot\left[h_{t-1}, x_{t}\right]+b_{o}\right) \\
& h_{t}=s_{t} * \tanh \left(C_{t}\right)
\end{aligned}
$$

Burada $w_{f}, w_{i}, w_{C}, w_{o}$ ağırlık matrislerini ve $b_{f}, b_{i}, b_{C}, b_{o}$ sapma vektörlerini temsil etmektedir. $\sigma(\cdot)$, kapı aktivasyon fonksiyonu olarak kullanılan lojistik sigmoid fonksiyonudur ve

$$
\sigma(x)=\frac{1}{1+e^{-x}}
$$

ile ifade edilir. $\tanh (\cdot)$, hiperbolik tanjant işlevidir; giriş ve çıkış bloğunun aktivasyon fonksiyonu

$$
\tanh (x)=\frac{e^{x}-e^{-x}}{e^{x}+e^{-x}}
$$

olarak kullanılır.

\subsection{Rüzgâr Hızı Zaman Serileri Veri Seti}

Çalışmada kullanılan rüzgâr hızı verileri Türkiye'nin Marmara bölgesi çevresindeki üç farklı meteoroloji istasyonundan toplanmıştır. Bu üç meteoroloji istasyonu Şekil 2'de gösterilen Bandırma, Bozcaada ve İpsala'da konumlandırılmıştır. Verilerin toplandığı bu bölgeler, Türkiye'nin en yüksek potansiyel rüzgâr enerjisine sahip konumları arasında yer almaktadır. Bu ölçüm istasyonları, bölgedeki diğer ölçüm istasyonlarından izole edilmiştir. Rüzgâr hızı ve yön ölçümleri 2008-2014 yılları arasında 6 ve 8 aylık bir dönem için yapılmışıtır. Her bir istasyondan yaklaşı 52.000 saatlik rüzgâr hızı ölçüm verisi toplanmıştır (Akçay and Filik 2017). Bu çalışmada kullanılan veri seti, her bir ölçüm istasyonundan toplanan 
verilerin 10 saatlik ortalamaları alınarak oluşturulmuştur. Her bir istasyon için 5.173 veriden oluşan rüzgâr hızı veri setinin \%15'lik kısmı test verisi olarak ayrılmıştır. Bandırma, Bozcaada ve İpsala istasyonlarından toplanan rüzgâr hızı zaman serisi verilerine ilişkin bazı istatistiksel değerler Tablo 1'de sunulmuştur. Tablo 1 'de, her bir ölçüm istasyonundan toplanan rüzgâr hızı verilerinin tümü, eğitim seti ve test seti için minimum, maksimum, ortalama ve standart sapma değerleri ayrı ayrı verilmiştir. Önerilen rüzgâr hızı tahmin modeli başarımının veri setinden bağımsız olduğunun gösterilmesi açısından bu istatistiksel değerlerin sunulması oldukça önemlidir.

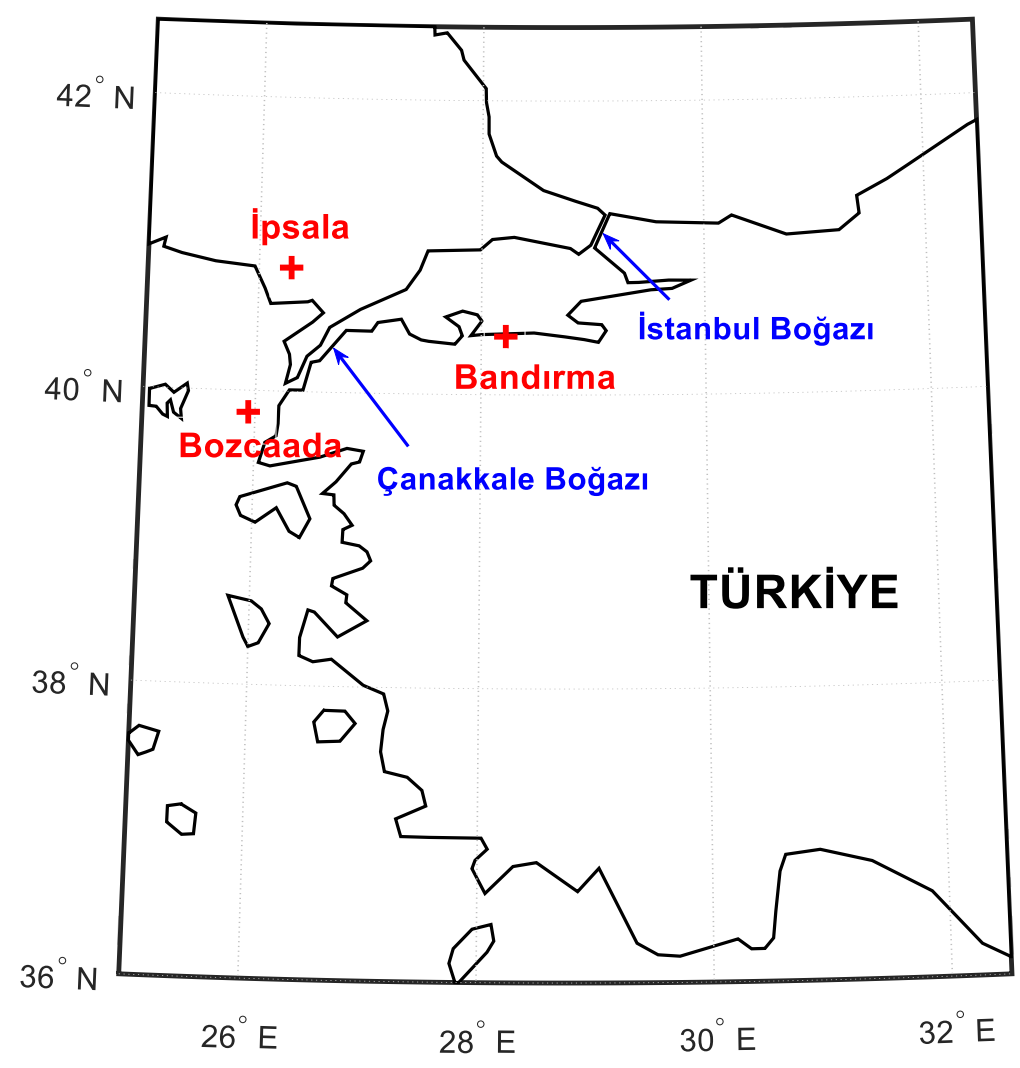

Şekil 2. Veri toplanan rüzgâr istasyonlarının konumları.

Tablo 1. Türkiye'nin Marmara bölgesindeki üç rüzgâr istasyonundan toplanan rüzgâr hızı zaman serisi verilerinin istatistiksel değerleri

\begin{tabular}{|c|c|c|c|c|c|c|}
\hline \multirow[t]{2}{*}{ Konum } & \multirow[t]{2}{*}{ Veri Seti } & \multirow[t]{2}{*}{$\begin{array}{l}\text { Örnek } \\
\text { Sayısı }\end{array}$} & \multicolumn{4}{|c|}{$\begin{array}{c}\text { İstatistiksel değerleri } \\
(\mathrm{m} / \mathrm{s})\end{array}$} \\
\hline & & & Minimum & Maksimum & Ortalama & $\begin{array}{l}\text { Standart } \\
\text { Sapma }\end{array}$ \\
\hline \multirow{3}{*}{ Bandırma } & Tümü & 5173 & 0.6 & 25.7 & 3.9893 & 2.5093 \\
\hline & Eğitim & 4397 & 0.7 & 25.7 & 4.0370 & 2.5426 \\
\hline & Test & 775 & 0.6 & 11.6 & 3.7145 & 2.2926 \\
\hline \multirow{3}{*}{ Bozcaada } & Tümü & 5173 & 0.5 & 30.5 & 5.8528 & 3.1660 \\
\hline & Eğitim & 4397 & 0.7 & 30.5 & 5.9617 & 3.2106 \\
\hline & Test & 775 & 0.5 & 17.5 & 5.2316 & 2.8233 \\
\hline \multirow{3}{*}{ İpsala } & Tümü & 5173 & 0.3 & 14.9 & 2.8671 & 1.5143 \\
\hline & Eğitim & 4397 & 0.3 & 14.9 & 2.9177 & 1.5406 \\
\hline & Test & 775 & 0.4 & 10.9 & 2.5785 & 1.3203 \\
\hline
\end{tabular}

\subsection{Performans Ölçütleri}

Çalışmada oluşturulan rüzgâr hızı tahmin modellerinin performansının değerlendirilmesinde Tablo 2'de verilen ortalama mutlak hata (mean absolute error-MAE), ortalama kare hata (mean squared error-MSE) ve kök ortalama kare hata (root mean square error-RMSE) performans ölçütleri kullanılmıştır. Kullanılan bu üç performans ölçütü, literatürdeki rüzgâr hızı modellerinin değerlendirilmesinde sıklıkla kullanılmaktadır. Bu üç performans ölçütü için, dizin değeri ne kadar küçük olursa, model performansı o kadar iyi olmaktadır. Belirtilen performans ölçütlerinin matematiksel ifadeleri Tablo 2'de sunulmuştur. 
Çalışmada incelenen rüzgâr hızı zaman serisi tahmin modellerinin geçerliliği ve güvenilirliği bu performans ölçütleri yardımıyla test edilmiştir.

\section{Deneysel Sonuçlar ve Tartışma}

Çalışmada önerilen EWT-LSTM rüzgâr hızı tahmin modeli, tekli LSTM, EMD-LSTM ve EEMD-LSTM modelleri ile birlikte Şekil 2'de gösterilen Bandırma, Bozcaada ve İpsala rüzgâr çiftliklerinden toplanan rüzgâr hızı veri setlerine uygulanmıştır. Modellerin başarımları MAE, MSE ve RMSE performans indeksleri ile ölçülmüştür. Rüzgâr hızı tahmini için ele alınan tüm modellerin performansı Tablo 3 'te sunulmuştur. Modeller her bir istasyon için 4.397 örnekten oluşan eğitim verisi ile eğitilmiştir. Modellerin performansı ise 775 örnekten oluşan ve modellerin eğitim aşamasında kullanılmayan test verisi üzerinde ölçülmüştür.

MAE, MSE ve RMSE performans ölçütlerine göre önerilen EWT-LSTM rüzgâr hızı tahmin modelinin kestirim doğruluğu Bandırma istasyonu için sırasıyla $0,0540,0,0046$ ve 0,0678 , Bozcaada istasyonu için sırasıyla $0,0896,0,0080$ ve 0,0720 , İpsala istasyonu için sırasıyla 0,0592, 0,0082 ve 0,0907'dir. Önerilen
EWT-LSTM rüzgâr hızı tahmin modeli diğer modellerle kıyaslandığında en iyi MAE, MSE ve RMSE değerlerine sahip olduğu görülmektedir. Ayrıştırma yöntemlerinin LSTM modeli üzerindeki etkisinin incelenebilmesi için EMD-LSTM ve EEMDLSTM modelleri oluşturulmuştur. Tekli LSTM modelinin MAE, MSE ve RMSE performans ölçütlerine göre tahmin başarımı Bandırma istasyonu için sırasıyla 1,0452, 1,8892 ve 1,3745, Bozcaada istasyonu için sırasıyla 1,4140, 3,2929 ve 1,8146, İpsala istasyonu için sirasiyla $0,7956,1,1318$ ve 1,0639 'dur. Tekli LSTM rüzgâr hızı tahmin modelinin çalışmada ele alınan diğer modellerle kıyaslandığında en kötü MAE, MSE ve RMSE değerlerine sahip olduğu görülmektedir.

Çalışmada ele alınan tüm rüzgâr hızı tahmin modellerinin Bandırma, Bozcaada ve İpsala istasyonları için elde edilen tahmin sonuçları sırasıyla Şekil 3-5'te sunulmuştur. Şekil 3-5 ve Tablo 3 birlikte değerlendirildiğinde önerilen EWT-LSTM modelinin rüzgâr hızının anlık değişimlerini tahmin etmede daha duyarlı ve başarılı olduğu görülmektedir. Önerilen EWT-LSTM modeli, tekli LSTM modeline kıyasla tahmin başarımını MAE, MSE ve RMSE performans indekslerine göre en az \%91 iyileştirmektedir.

Tablo 2. Rüzgâr hızı tahmin modellerin performansının değerlendirilmesinde kullanılan ölçütler

\begin{tabular}{lll}
\hline Ölçüt & Tanım & Denklem \\
\hline MAE & Mean absolute error & $M A E=\frac{1}{N} \sum_{i=1}^{N}\left|p_{\text {tahmin }}^{i}-p_{\text {gerçek }}^{i}\right|$ \\
MSE & Mean squared error & $M S E=\frac{1}{N} \sum_{i=1}^{N}\left(p_{\text {tahmin }}^{i}-p_{\text {gerçek }}^{i}\right)^{2}$ \\
RMSE & Root mean square error & $R M S E=\sqrt{\frac{1}{N} \sum_{i=1}^{N}\left(p_{\text {tahmin }}^{i}-p_{\text {gerçek }}^{i}\right)^{2}}$ \\
\hline
\end{tabular}

Tablo 3. Tahmin modellerinin çeşitli rüzgâr istasyonlarından toplanan rüzgar hızı zaman serileri üzerindeki başarımı

\begin{tabular}{lllll}
\hline İstasyon & Model & MAE & MSE & RMSE \\
\hline \multirow{3}{*}{ Bandirma } & LSTM & 1.0452 & 1.8892 & 1.3745 \\
& EMD-LSTM & 0.7169 & 0.9648 & 0.9822 \\
& EEMD-LSTM & 0.4219 & 0.3184 & 0.5642 \\
& EWT-LSTM & 0.0540 & 0.0046 & 0.0678 \\
\hline \multirow{3}{*}{ Bozcaada } & LSTM & 1.4140 & 3.2929 & 1.8146 \\
& EMD-LSTM & 0.9721 & 1.9959 & 1.4128 \\
& EEMD-LSTM & 0.6220 & 0.6793 & 0.8242 \\
\multirow{3}{*}{ İpsala } & EWT-LSTM & 0.0896 & 0.0080 & 0.0720 \\
& LSTM & 0.7956 & 1.1318 & 1.0639 \\
& EMD-LSTM & 0.4378 & 0.4012 & 0.6334 \\
& EEMD-LSTM & 0.3703 & 0.2806 & 0.5297 \\
& EWT-LSTM & 0.0592 & 0.0082 & 0.0907 \\
\hline
\end{tabular}


Ayrıştırma yöntemlerinin derin öğrenme yaklaşımı üzerindeki etkisinin incelenebilmesi için EMD-LSTM ve EEMDLSTM modelleri oluşturulmuştur. EMD-LSTM modeli, tekli LSTM modeline kıyasla tahmin başarımını MAE performans indeksine göre en az \%31, MSE performans indeksine göre en az $\% 39$ ve RMSE performans indeksine göre en az \%22 iyileştirmektedir. EEMD-LSTM modeli, tekli LSTM modeline kıyasla tahmin başarımını MAE performans indeksine göre en az $\% 53$, MSE performans indeksine göre en az \%75 ve RMSE performans indeksine göre en az \%50 iyileştirmektedir. EEMDLSTM modelinin EMD-LSTM modeline kıyasla tahmin başarımı iyileştirdiği de görülmektedir. Bu iyileşmenin temel nedeni, EEMD’nin gürültünün birçok önemli istatiksel özelliğini kullanmasıdır. Algoritmaya eklenen sonlu gürültünün, mod karıştırma problemini büyük ölçüde ortadan kaldırdığı elde edilen sonuçlarla doğrulanmaktadır.

Önerilen EWT-LSTM modeli, EEMD-LSTM modeline kıyasla tahmin başarımını MAE performans indeksine göre en az \%84, MSE performans indeksine göre en az \%97 ve RMSE performans indeksine göre en az \%82 iyileştirmektedir. Ayrıştırma yöntemlerinden EWT'nin derin öğrenme yaklaşımında bu kadar yüksek bir başarıma sahip olmasının nedeni, uygun segmentasyon ile içsel modlarının elde edilmesi ve belirlenen her bir segmente karşılık gelen ölçekleme ve dalgacık fonksiyonlarının kullanılmasıdır. Durağan olmayan rüzgar hızının tahmininde önerilen EWT ayrıştırma yönteminin tatmin edici performans sergilediği görülmektedir.

BANDIRMA

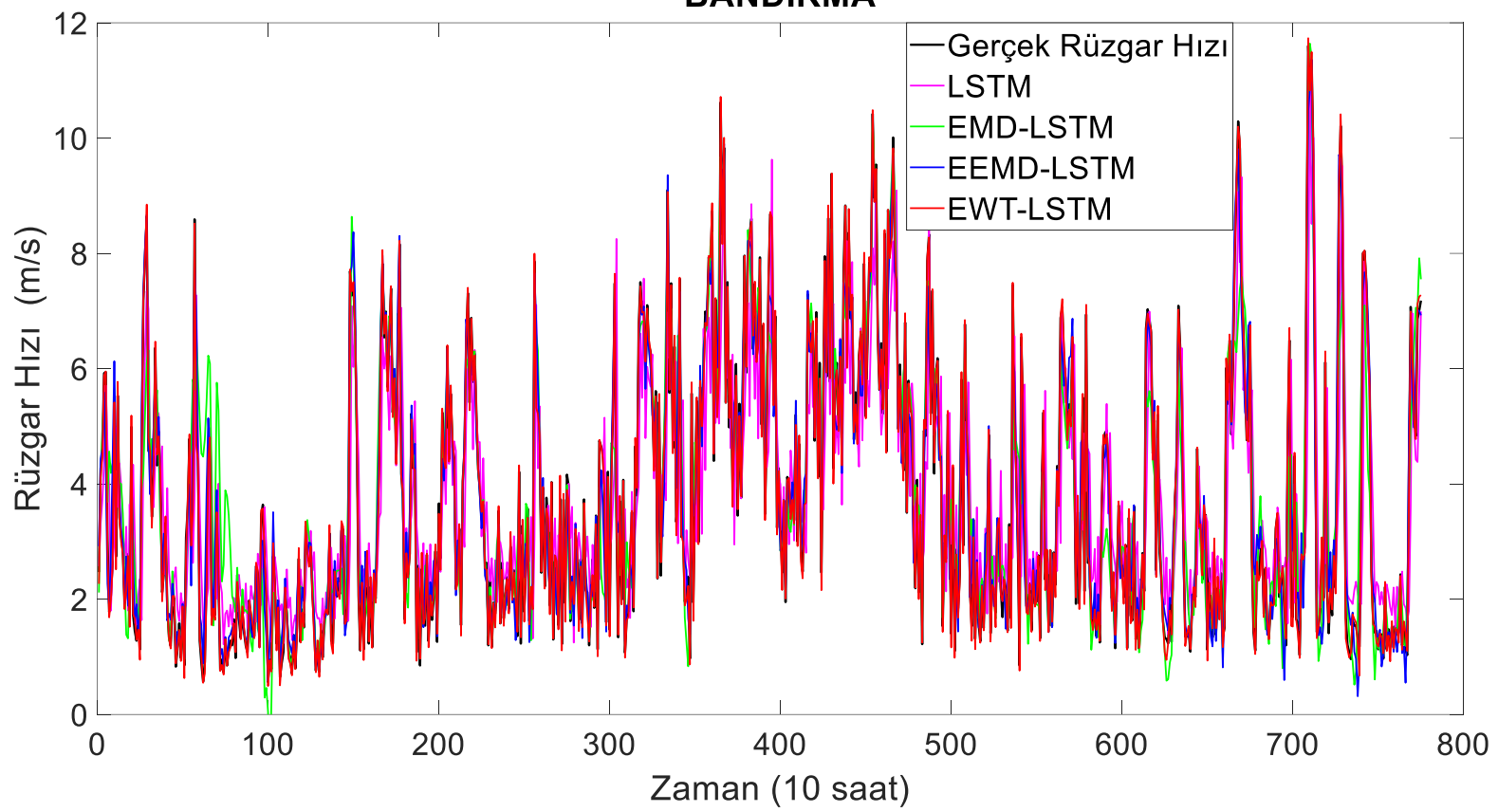

Şekil 3. Bandırma istasyonu için çeşitli ayrıştırma yöntemleri kullanılarak LSTM modelleri ile elde edilen rüzgâr hızı tahmin sonuçları.

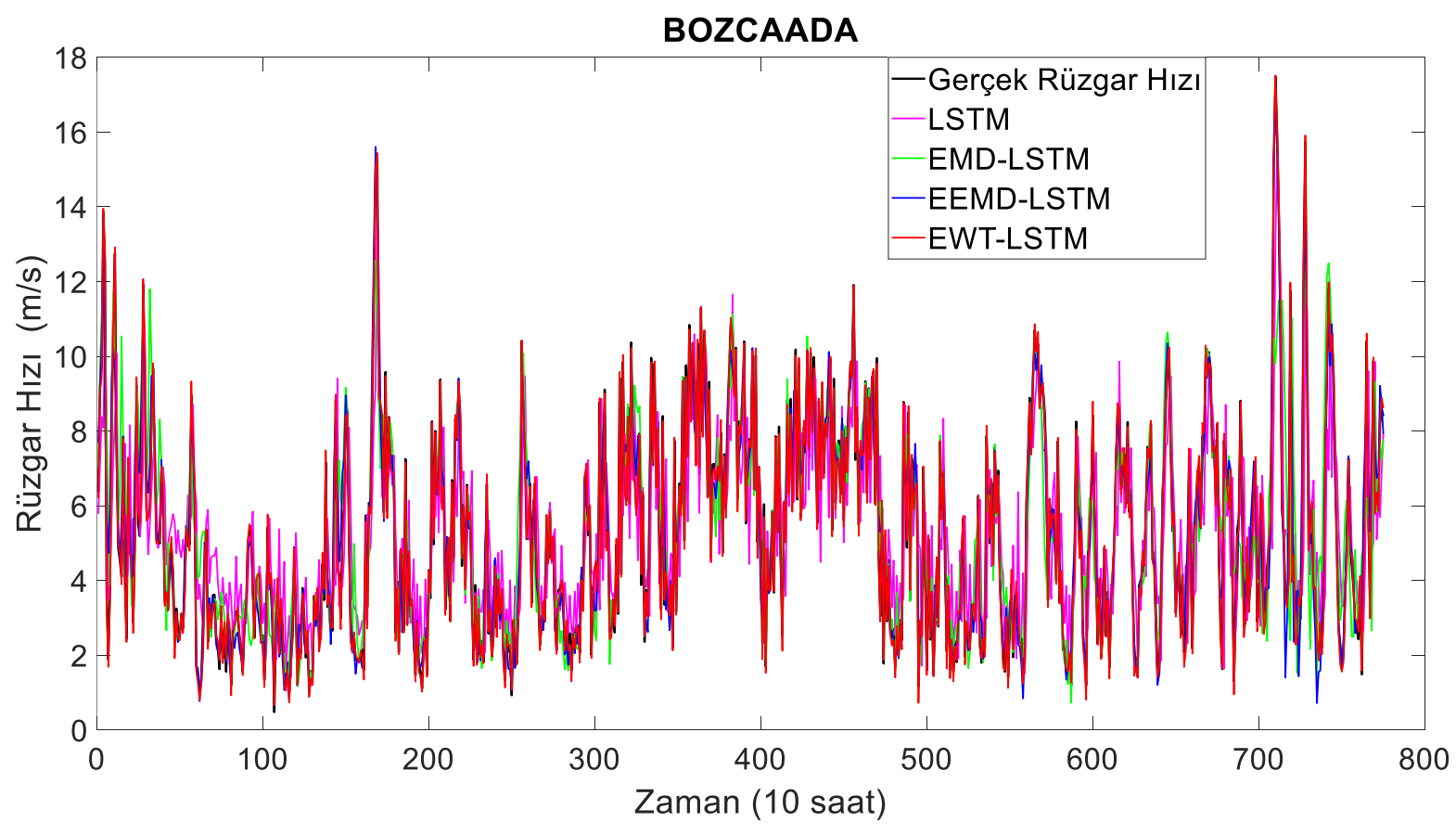




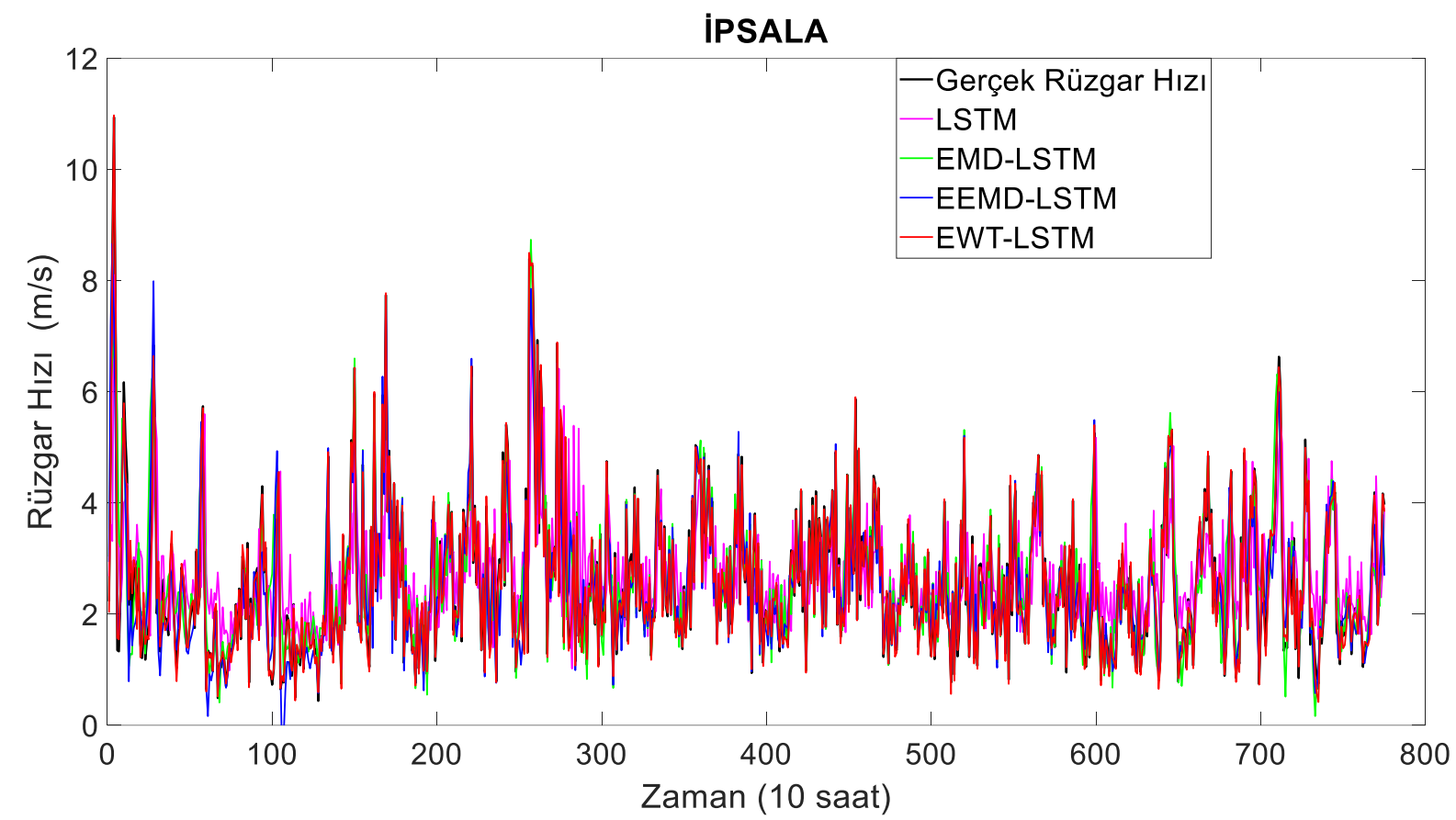

Şekil 5. Ípsala istasyonu için çeşitli ayrıştırma yöntemleri kullanılarak LSTM modelleri ile elde edilen rüzgâr hızı tahmin sonuçları.

\section{Sonuçlar}

Rüzgâr hızının güvenilir ve yüksek doğrulukla tahmin edilmesi, rüzgâr gücünün etkin bir şekilde kullanılabilmesi ve işletilebilmesi açısından oldukça önemlidir. Rüzgâr hızının durağan olmaması ve stokastik yapısı, rüzgâr hızı tahmininde ayrıştırma yöntemlerini ön plana çıkarmaktadır. Bu çalışmada, rüzgâr hızının yüksek doğrulukla tahmini için ayrıştırma yöntemlerinin derin öğrenme yaklaşımı üzerindeki etkisi araştırılmıştır. Önerilen EWT ayrıştırma yönteminin derin öğrenme yöntemlerinden LSTM üzerindeki etkisi EMD ve EEMD ayrıştırma yöntemleri ile kıyaslanmıştır. Önerilen EWTLSTM modeli ile birlikte çalışmada ele alınan LSTM, EMDLSTM ve EEMD-LSTM modellerinin tahmin başarımlar MAE, MSE ve RMSE metrikleriyle ölçülmüştür. Önerilen modelin dayanıklılığı Bandırma, Bozcaada ve İpsala'da kurulu olan üç farklı istasyondan alınan rüzgâr hızı verileri üzerinde test edilmiştir. Ayrıştırma yöntemlerinin LSTM üzerindeki etkisinin belirlenebilmesi için çalışmada oluşturulan modeller tekli LSTM modeli ile kıyaslanmıştır. EMD ayrıştırma yönteminin LSTM modelinin tahmin başarımını MAE performans ölçütüne göre en az \%31 ile \%44 arasında iyileştirdiği görülmektedir. EEMD ayrıştırma yönteminin LSTM modelinin tahmin başarımını MAE performans ölçütüne göre en az \%53 ile \%59 arasında, EWT ayrıştırma yönteminin ise LSTM modelinin tahmin başarımını en az $\% 92$ ile $\% 95$ arasında iyileştirdiği belirlenmiştir. Önerilen model tekli LSTM modeli ile kıyaslandığında tahmin başarımını MSE performans ölçütüne göre en az \%99, RMSE performans ölçütüne göre en az \%91 ile \%95 arasında iyileştirmektedir. Önerilen EWT-LSTM modelinin rüzgâr hızının anlık değişimlerini tahmin etmede oldukça başarılı olduğu görülmüştür. Gelecek çalışmalarda, EWT'nin ayrıştırılan bantlarının her birinin derin öğrenme modelinin tahmin başarımı üzerindeki etkisinin incelenmesi düşünülmektedir.

\section{Kaynakça}

Akçay, H. \& Filik, T. (2017). Short-term wind speed forecasting by spectral analysis from long-term observations with missing values. Applied Energy, 191, 653-662.

Cadenas, E., Rivera, W., Campos-Amezcua, R., \& Heard, C. (2016). Wind speed prediction using a univariate ARIMA model and a multivariate NARX model. Energies, 9(2), 109124.

Chen, J., Zeng, G. Q., Zhou, W., Du, W., \& Lu, K. D. (2018). Wind speed forecasting using nonlinear-learning ensemble of deep learning time series prediction and extremal optimization. Energy Conversion and Management, 165, 681-695.

Çakır, M. T. (2010). Türkiye'nin rüzgâr enerji potansiyeli ve $A B$ ülkeleri içindeki yeri. Politeknik Dergisi, 13(4), 287-293.

De Giorgi, M. G., Ficarella, A., \& Tarantino, M. (2011). Assessment of the benefits of numerical weather predictions in wind power forecasting based on statistical methods. Energy, 36(7), 3968-3978.

Du, P., Wang, J., Guo, Z., \& Yang, W. (2017). Research and application of a novel hybrid forecasting system based on multi-objective optimization for wind speed forecasting. Energy Conversion and Management, 150, 90-107.

Hochreiter, S. \& Schmidhuber, J. (1997). Long short-term memory. Neural Computation, 9(8), 1735-1780.

Hu, Y. L., \& Chen L. (2018). A nonlinear hybrid wind speed forecasting model using LSTM network, hysteretic ELM and differential evolution algorithm. Energy Conversion and Management, 173, 123-142.

Gilles, J. (2013). Empirical wavelet transform. IEEE Transactions on Signal Processing, 61(16), 3999-4010.

Huang, N. E., Shen, Z., Long, S. R., Wu, M. C., Shih, H. H., Zheng, Q., Yen, N. C., Tung, C. C., \& Liu H. H. (1998). The empirical mode decomposition and the Hilbert spectrum for 
nonlinear and non-stationary time series analysis. Proceedings of the Royal Society of London, Series A: Mathematical, Physical and Engineering Sciences, 454(1971), 903-995.

Huang, N. E., Wu, M. L. C., Long, S. R., Shen, S. S., Qu, W., Gloersen, P., \& Fan K. L. (2003). A confidence limit for the empirical mode decomposition and Hilbert spectral analysis. Proceedings of the Royal Society of London, Series A: Mathematical, Physical and Engineering Sciences, 459(2037), 2317-2345.

Jiang, Y. \& Huang, G. (2017). Short-term wind speed prediction: hybrid of ensemble empirical mode decomposition, feature selection and error correction. Energy Conversion and Management, 144, 340-350.

Karasu, S., Altan, A., Saraç, Z., \& Hacıoğlu, R. (2017). Estimation of fast varied wind speed based on NARX neural network by using curve fitting. International Journal of Energy Applications and Technologies, 4(3), 137-146.

Karasu, S., Altan, A., Saraç, Z., \& Hacioğlu, R. (2017b). Prediction of wind speed with non-linear autoregressive (NAR) neural networks. 25th IEEE Signal Processing and Communications Applications Conference, 1-4, Antalya.

Lange, M. \& Focken, U. (2006). Physical approach to short-term wind power prediction, Berlin, Germany: Springer, 3, 22-38.

Li, G. \& Shi, J. (2010). On comparing three artificial neural networks for wind speed forecasting. Applied Energy, 87(7), 2313-2320.

Li, H., Wang, J., Lu, H., \& Guo, Z. (2018). Research and application of a combined model based on variable weight for short term wind speed forecasting. Renewable Energy, 116, 669-684

Liu, H., Chen, C., Tian, H. Q., \& Li, Y. F. (2012). A hybrid model for wind speed prediction using empirical mode decomposition and artificial neural networks. Renewable Energy, 48, 545-556.

Liu, H., Tian, H. Q., Li, Y. F., \& Zhang, L. (2015). Comparison of four adaboost algorithm based artificial neural networks in wind speed predictions. Energy Conversion and Management, 92, 67-81.

Liu, H., Tian, H. Q., Liang, X. F., \& Li, Y. F. (2015). Wind speed forecasting approach using secondary decomposition algorithm and Elman neural networks. Applied Energy, 157, 183-194.

Liu, H., Tian, H., Liang, X., \& Li, Y. (2015). New wind speed forecasting approaches using fast ensemble empirical model decomposition, genetic algorithm, mind evolutionary algorithm and artificial neural networks. Renewable Energy, 83, 1066-1075.

Liu, H., Mi, X., \& Li, Y. (2018). Smart deep learning based wind speed prediction model using wavelet packet decomposition, convolutional neural network and convolutional long short term memory network. Energy Conversion and Management, $166,120-131$.
Liu, H., Mi, X. W., \& Li, Y. F. (2018b). Wind speed forecasting method based on deep learning strategy using empirical wavelet transform, long short term memory neural network and Elman neural network. Energy Conversion and Management, 156, 498-514.

Ma, X., Jin, Y., \& Dong, Q. (2017). A generalized dynamic fuzzy neural network based on singular spectrum analysis optimized by brain storm optimization for short-term wind speed forecasting. Applied Soft Computing, 54, 296-312.

Mohandes, M., Rehman, S., \& Rahman, S. M. (2011). Estimation of wind speed profile using adaptive neuro-fuzzy inference system (ANFIS). Applied Energy, 88(11), 4024-4032.

Riahy, G. H. \& Abedi, M. (2008). Short term wind speed forecasting for wind turbine applications using linear prediction method. Renewable Energy, 33(1), 35-41.

Sainath, T. N., Vinyals, O., Senior, A., \& Sak, H. (2015). Convolutional, long short-term memory, fully connected deep neural networks. IEEE International Conference on Acoustics, Speech and Signal Processing, Brisbane, Australia, 4580-4584.

Scarlat, N., Dallemand, J. F., Monforti-Ferrario, F., Banja, M., \& Motola, V. (2015). Renewable energy policy framework and bioenergy contribution in the European Union-An overview from national renewable energy action plans and progress reports. Renewable and Sustainable Energy Reviews, 51, 969-985.

Sfetsos, A. (2000). A comparison of various forecasting techniques applied to mean hourly wind speed time series. Renewable Energy, 21(1), 23-35.

Sun, W. \& Wang, Y. (2018). Short-term wind speed forecasting based on fast ensemble empirical mode decomposition, phase space reconstruction, sample entropy and improved backpropagation neural network. Energy Conversion and Management, 157, 1-12.

Wu, Z. \& Huang, N. E. (2009). Ensemble empirical mode decomposition: A noise-assisted data analysis method. Advances in Adaptive Data Analysis, 1(1), 1-41.

Yu, C., Li, Y., \& Zhang, M. (2017). Comparative study on three new hybrid models using Elman neural network and empirical mode decomposition based technologies improved by singular spectrum analysis for hour-ahead wind speed forecasting. Energy Conversion and Management, 147, 7585.

Zhang, X., Lai, K. K., \& Wang S. Y. (2008). A new approach for crude oil price analysis based on empirical mode decomposition. Energy Economics, 30(3), 905-918. 